\title{
AMÉRICA LATINA EN EL SIGLO XXI: AVANCES Y RETROCESOS EN LAS PAUTAS DE DESARROLLO SOCIAL
}

\section{Latin america in the 21st Century: avanças e recoils in the social development guidelines}

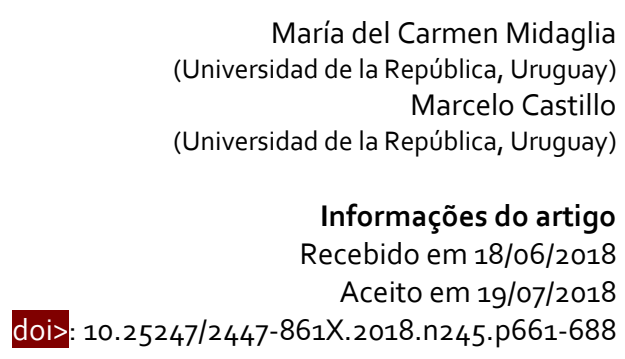

\begin{abstract}
Resumen
A inicios del siglo XXI América Latina inauguró una etapa de recuperación económica acompañada de un importante cambio político, relativo a que fuerzas partidarias de izquierda asumieron los gobiernos en un conjunto de países. En ese período, las naciones del Cono Sur (Brasil, Argentina, Chile y Uruguay) registraron mejoras significativas en materia de bienestar que se explican no sólo por el propio crecimiento de la época, sino también porque la pugna distributiva se procesó en sistemas democráticos. Las explicaciones académicas suponían que, en fase de desaceleración económica regional, se producirían ajustes moderados esencialmente por la propia dinámica democrática. El objetivo del presente artículo es mostrar los avances e innovaciones en materia de protección social en el Cono Sur en los últimos quince años. Simultáneamente como objetivo complementario, se pretende ensayar explicaciones para un escenario de coyuntura, sobre las reformulaciones que se están procesando en materia de protección tendientes a limitar y recortar las prestaciones públicas.
\end{abstract}

Palabras claves: Bienestar regional. Reforma social. Democracia y actores colectivos.

\section{Abstract}

At the beginning of the 21st century, Latin America inaugurated a stage of economic recovery accompanied by an important political change, related to which leftwing forces assumed the governments in a group of countries. During this period, the countries of the Southern Cone (Brazil, Argentina, Chile and Uruguay) recorded significant improvements in welfare that are explained not only by the economic growth, but also by the distributive struggle was processed in democratic systems. The academic explanations assumed that, in the phase of regional economic slowdown, moderate adjustments would be produced essentially by the democratic dynamic itself. The objective of this article is to show the advances and innovations in social protection in the Southern Cone in the last fifteen years. Simultaneously as a complementary objective, it is intended to test explanations for a conjuncture scenario, on the reformulations that are being processed in terms of protection tending to limit and cut public benefits.

Keywords: Regional welfare. Social reform. Democracy and collective actors. 


\section{Introducción}

América Latina, específicamente el Cono Sur, Argentina, Brasil, Chile y Uruguay se han caracterizado por la institucionalización relativamente temprana de sistemas básicos de bienestar, aunque incompletos y con variaciones territoriales según país de referencia. (MESA LAGO, 1978; SÁTYRO; CUNHA, 2015; MIDAGLIA y ANTÍA, 2017).

No obstante, ese rasgo distintivo de la protección pública de ese grupo de naciones, este continente históricamente ha presentado significativos índices de desigualdad socioeconómica, acompañado de altos niveles de pobreza dependiendo de la etapa y orientación del desarrollo socioeconómico.

La región en su conjunto comienza a transitar el siglo XXI retomando la senda del crecimiento, pese a que, en esa ocasión, algunos países del sur (en particular Argentina y Uruguay) se encontraban transcurriendo una severa crisis económica, que tendió a atenuarse a partir del año 2002. En esa etapa se procesó un importante cambio político, relativo a que fuerzas partidarias de orientación de izquierda o progresistas asumieron los gobiernos nacionales en una serie de países, lo que se denominó "el giro a la izquierda" (ARDITI, 2009).

En un contexto de desarrollo económico, con aumentos constantes del Producto Bruto Interno (PIB) desde el año 2005 hasta el 2009¹ (período en que emergen algunos problemas productivos y comerciales) se registran mejoras significativas en materia de bienestar (pobreza y desigualdad, entre otros) que se explican, no sólo por el propio crecimiento sino también por la pugna distributiva que se procesa en los sistemas democráticos (CEPAL, 2013; MIDAGLIA y CASTILLO, 2014).

No hay lugar a duda que Latinoamérica tuvo avances socioeconómicos en los últimos quince años, que trascendieron las mejoras de los clásicos indicadores sociales, en la medida que supusieron reformulaciones de políticas públicas estratégicas que impactan en las condiciones de vida de la población. Entre los cambios generales impulsados, cabe destacar: las intervenciones públicas en el mercado de empleo, relativas a re-regulaciones

1 Desde el año 2005 hasta el 2009 América Latina, tuvo tasas de crecimiento del PIB que oscilaron entre 5,70 (2005) y 6,30 (2007). Posteriormente a la abrupta caída del año 2009, año en el que se registró un pico de 0,08 , América Latina recuperó el período de auge llegando al pico de crecimiento en el año 2011 que fue de 5,24 (Datos tomados de la página electrónica del World Development Indicators, Banco Mundial). 
laborales, formalización de la fuerza de trabajo, aumentos de salario mínimo, entre otras, y en el área de la asistencia social, iniciativas referidas a la promoción de apoyos monetarios y distintos servicios a los hogares en situación de pobreza y vulnerabilidad.

Más allá de la diferenciación de esas arenas de políticas sociales en términos de su contribución al desarrollo y a los procesos de integración social, se identifican pautas compartidas en las revisiones regionales realizadas, tendientes a la universalización de las prestaciones en clave de facilitar el acceso, incrementar los beneficios y extender su espectro de acción incorporando a nuevos grupos sociales (MARTíNEZ FRANZONI; SÁNCHEZ-ANCOCHEA, 2014).

La ampliación de la oferta social estuvo acompañada de procesos de institucionalización de diversas protecciones a través de la asignación de recursos de los presupuestos nacionales, lo que supuso cierto nivel de aumento del gasto público social (BARBA, 2016). De esta manera, se verificaba el reposicionamiento del Estado en tanto agente de provisión de bienes públicos y en consecuencia un moderado re-intervencionismo en la mayoría de las naciones de la región (MIDAGLIA y CASTILLO, 2014).

En este nuevo escenario económico y político se comenzó analizar las posibilidades que tenía América Latina de completar sus informales sistemas de seguridad social (WOOD, 2013; GOUGH; WOOD, 2004), de moderar la distribución clientelar de los beneficios (DOS SANTOS, 1987; KURTZ, 2004) y de consagrar esquemas universales de protección transitando caminos alternativos a los utilizados por los países europeos, teniendo en cuenta sus legados de bienestar y el modelo vigente de desarrollo (MARTÍNEZ FRANZONI; SÁNCHEZ-ANCOCHEA, 2014).

Existía cierto consenso académico y político que ese estado de situación social favorable no se explicaba solamente por la bonanza económica que vivía el continente, sino por la incidencia de un conjunto de variables políticas que consagraron políticas públicas de inversión y aseguramiento social. Desagregando los factores políticos gravitantes en el refuerzo de servicios e iniciativas sociales, figuraban: la competencia política democrática y la movilización de los sectores populares, en su mayoría con inserción laboral informal, 
proclives a las políticas de asistencia (GARAY, 2010)리 los gobiernos de orientación de izquierda, y en particular el tipo de izquierda en el poder, mejorando los derechos laborales individuales y en algunos casos colectivos (COOK; BAZLER, 2013); y en otros análisis, se combinaban estos factores, aplicando "la teoría de los recursos de poder", en los que actores colectivos pro-distribución (sindicatos) y las fuerzas políticas progresistas lograron incorporar en la agenda pública nuevas demandas e intereses sociales (CARNEIRO, 2017).

Atendiendo los factores políticos arriba anotados, se suponía que, en fase de desaceleración económica regional, se producirían ajustes en el campo de la protección los que no se traducirían en una desarticulación del conjunto de políticas sociales, ya que la propia dinámica democrática y las expectativas ciudadanas de bienestar bloquearían las posibilidades de impulsar un "recorte" radical en ese campo de acción (Filgueira, 2013). En ese nuevo contexto, se admitía la rotación de las fuerzas políticas en el gobierno, específicamente el arribo de partidos liberales o conservadores, que si bien responderían a sus bases electorales simultáneamente se garantizarían el apoyo de los sectores más desfavorecidos, y en consecuencia promoverían sistemas más restrictivos de políticas sociales (GARAY, 2010).

Sin embargo, los supuestos o hipótesis arriba enunciadas no parecen comprobarse cabalmente en el presente de la región, en el que se asiste a la instalación de gobiernos calificados de opción de derecha, debido a sus posiciones neoliberales en lo económico y de limitación de la inversión social.

El objetivo del presente trabajo es mostrar los avances e innovaciones en materia de protección social (fundamentalmente en el sector de asistencia y el laboral), que se llevaron a cabo en los países del Cono Sur (Argentina, Brasil, Chile y Uruguay) en los últimos quince años. Simultáneamente como objetivo complementario, se pretende ensayar explicaciones para un escenario de coyuntura, sobre las serias reformulaciones que se están procesando en el "edificio de bienestar instituido", tendientes a limitar y recortar las prestaciones públicas.

Las fuentes de información en las que se respalda este trabajo refieren a datos

2 El trabajo de Candelaria Garay refiere a la fase de expansión de las políticas de asistencia (fines de los años '9o y primera década de los 2000) que se dirige a la población vulnerable, calificada por la autora de "outsiders". 
secundarios de indicadores sociales y rendimientos de prestaciones públicas, así como evaluaciones de políticas sectoriales y de paquetes agregados de políticas sociales.

Este documento se organiza en cinco secciones específicas, a saber: además de la introducción, el apartado siguiente aborda los legados regionales de bienestar y los principales factores políticos que incidieron en los formatos de provisión pública consagrados. En el tercer ítem se exponen las mejoras sociales logradas desde inicio del siglo XXI hasta el año 2015. A continuación, se plantea el retroceso que se está evidenciando en materia de protección en el Cono Sur y se ensayan algunas explicaciones sobre la presente coyuntura económica y política. Finalmente, el trabajo concluye con algunas consideraciones acerca del futuro del bienestar.

\section{Los legados de bienestar latinoamericanos y la debilidad democrática}

El desarrollo de los esquemas de bienestar de los países europeos líderes en la intervención pública en este campo de acción, estuvo asociada con la expansión de la democracia de masas, el fortalecimiento de los partidos socialdemócratas o laboristas, así como con la organización de actores colectivos pro-redistribución en un modelo de desarrollo en clave "proteccionista" (MARSHALL, 1950; PETER FLORA, 1981, WILENSKY, 1975).

América Latina en su conjunto se caracterizó por la instalación de Estados Sociales incompletos, con significativos niveles de informalidad en la distribución de beneficios públicos (GOUGH; WOOD, 2004), que ponen en evidencia la ausencia o debilidad de los factores políticos arriba anotados, más allá de los problemas de inserción internacional y de las estrategias de desarrollo adoptadas en la historia regional moderna, que también frenaron la promoción de robustos esquemas de protección social (OCAMPO, 2011).

Es así que, cuando se intenta explicar los déficits de provisión de bienes públicos en el continente, se consideran de manera destacada, la incidencia que han tenido las múltiples interrupciones democráticas a lo largo del siglo XX, (HUBER; STEPHENS, 2012).

Las administraciones autoritarias tendieron a reprimir las demandas sociales probienestar, con el consiguiente control y desarticulación de actores colectivos favorables a la redistribución económica. En ocasiones, estos "regímenes de excepción" se combinaron con estrategias políticas populistas, que supusieron negociaciones a "puertas cerradas" sobre 
diversas pautas de protecciones económicas y sociales, con la finalidad de tramitar el conflicto capital-trabajo, y simultáneamente asegurar, entre otros cometidos, la incorporación a la vida moderna de amplios segmentos poblacionales (DOS SANTOS, 1987; FILGUEIRA, 2013)

En este contexto, las organizaciones populares regionales tendieron a ser débiles, fragmentadas y en ocasiones cooptadas por los grupos o partidos políticos que administraban el Estado, sin posibilidades efectivas de incluir sus reivindicaciones en la agenda pública.

De acuerdo a Huber y Stephens (2012), la democracia es una pre-condición para alcanzar dosis de redistribución económica en los países occidentales, en la medida que permite el desarrollo de partidos de izquierda que tramitan las demandas de los sectores asalariados y así se logra modificar la correlación de fuerzas sociopolíticas que frenan la distribución de la riqueza. La clásica teoría de los recursos de poder logró explicar los beneficios que trae aparejado la vinculación izquierda y sindicatos en clave de protección social y los impactos producidos en la moderación del patrón de desigualdad de las sociedades modernas (KORPI, 1985).

Resulta evidente, que América Latina no tuvo condiciones políticas y económicas hasta el siglo XXI de generar un escenario democrático estable, donde las fuerzas partidarias de diferente orientación política compitieran por la construcción de paquetes de políticas públicas que contemplaran la redefinición de los parámetros distributivos restrictivos que predominaron en el continente, aunque admitiendo cierta variabilidad según subregión y país de referencia.

De ahí los nefastos saldos sociales que han caracterizado a la historia regional, expresados en términos de niveles de pobreza y desigualdad, poniendo en evidencia la exclusión de amplios segmentos de población de condiciones básicas de bienestar.

Las distintas clasificaciones de los esquemas de seguridad social que tuvieron lugar en el continente de acuerdo a las distintas fases de acumulación capitalista, ponen en evidencia lo limitado de esos sistemas, transformándose en legados que condicionan la expansión de futuras protecciones.

Cabe mencionar brevemente algunas de esas tipologías, de modo de ilustrar la heterogeneidad regional imperante en materia políticas sociales y las deficitarias intervenciones públicas en este campo de acción. 
Atendiendo a los programas de pensiones, los seguros de enfermedad/maternidad y el grado de desarrollo alcanzado en estas medidas públicas, Mesa Lago (1986 y 2001) identificó tres diferentes grupos de países en la región. Un primer grupo de países pioneros, establecieron sistemas de seguridad social de amplia cobertura, aunque con segmentación y/o estratificación de beneficios, en la década del veinte e inicios de la del treinta del siglo pasado (Uruguay, Argentina, Chile, Cuba, Brasil y Costa Rica). Otro grupo, de países denominados intermedios, llevaron adelante políticas de menor cobertura de población en la década del cuarenta (Panamá, México, Perú, Colombia, Bolivia, Ecuador y Venezuela) y, por último, el grupo de países llamados como tardíos fijaron políticas de seguridad social de escasa cobertura en las décadas del cincuenta y sesenta (Paraguay, República Dominicana, Guatemala, El Salvador, Nicaragua, Honduras y Haití).

Las importantes diferencias en términos de población cubierta en los diversos países llevaron a otro tipo de clasificación de los sistemas sociales de la región: universales estratificados, duales y excluyentes (FILGUEIRA, 1998 y 2005). En el primero de los tipos, integrado por Argentina, Chile y Uruguay, se brindó protección sanitaria, de seguridad social y educación a la mayor parte de la población, pero con importantes diferencias en cuánto a la calidad de las prestaciones. El empleo formal era el principal mecanismo de acceso a las prestaciones sociales. En el segundo de los tipos, el dual en el que se ubican Brasil y México, se desarrolló de forma casi universal la educación primaria pero un acceso estratificado a la salud y escasa cobertura en seguridad social. Por último, se identifican los regímenes excluyentes (la mayoría de países centroamericanos y algunos andinos) tuvieron "sistemas elitistas de seguro social (accedía alrededor del 20\% de los ciudadanos) y en dual en materia de educación en la medida que tenía mayor cobertura, pero su calidad era altamente segmentada (FILGUEIRA, 1998: 15).

A fines del siglo pasado, con independencia del contexto general de aplicación del paradigma neoliberal, cada país de la región manejó de manera diferente la crisis de la deuda de la década del ochenta y el recambio efectivo de su modelo de desarrollo. La trayectoria seguida se explicó en base a los diferentes legados de bienestar y el patrón de distribución de recursos de poder que tenía cada país, en términos de relación entre el sistema de partidos y los movimientos sociales (HUBER y STEPHENS, 2012; MIDAGLIA, 2009).

El decálogo reformista guiado por el paradigma neoliberal consistió en: i) el aumento 
de la precariedad laboral debido a la generalización de la supresión de las negociaciones laborales colectivas así como por el incremento de empleos mayormente precarios informales o subempleos- (OIT, 1999; OIT, 2010; OIT, 2013; Vega - Ruiz, 2004); ii) la configuración de matrices de protección social dualizadas y/o fragmentadas en la atención de las problemáticas sociales - básicamente estructuradas por un lado en numerosas intervenciones asistenciales basadas en la categorización "pobre - no pobre"; III) y por otro recortes intervenciones sectoriales públicas y la introducción del mercado como un importante agente proveedor de bienes sociales estratégicos. En suma el modelo de bienestar emergente centro sus procesos de ajuste en la disputa basada en los medios de gestión más que en la de los fines sociopolíticos que se pretendía alcanzar (FILGUEIRA, 1997; MIDAGLIA; CASTILLO, 2009).

\section{Los avances de la protección en la región y particularmente en el Cono Sur}

Los primeros años del siglo XXI, específicamente a partir de 2004 la región comenzó a vivir una época de bonanza económica asociada a de dosis de distribución de la riqueza en un contexto de pleno funcionamiento democrático. Esa convivencia entre crecimiento y estabilidad política trajo aparejado resultado favorable en materia de bienestar.

a) Disminución en los niveles de Pobreza y Desigualdad

Las mejoras en los indicadores sociales que se han registrado en Latinoamérica relativos a la incidencia de pobreza y desigualdad son indicativos de un cambio de época. De acuerdo a la siguiente gráfica el porcentaje de personas por debajo de la línea de pobreza cayó de un 45,9 en el año 2002 a un 30,7 en el 2017. 
Gráfica 1. América Latina: evolución de la pobreza y de la indigencia, 1980 - 2017 (Porcentaje de personas)

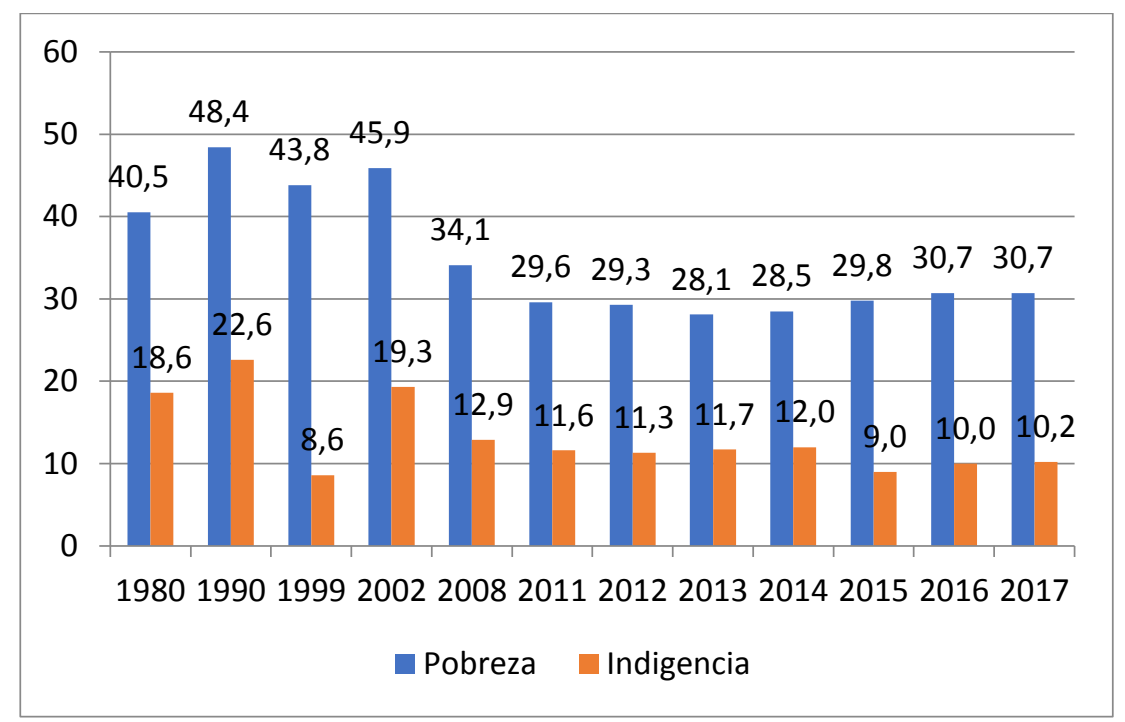

Fuente: Comisión Económica para América Latina y el Caribe (CEPAL), sobre la base de tabulaciones especiales de las encuestas de hogares de los respectivos países.

Para algunos analistas, la disminución de estas situaciones de pobreza y vulnerabilidad representan avances en las llamadas áreas "blandas" del desarrollo (FILGUEIRA, 2011), es decir, en aquellos campos socioeconómicos susceptibles de rápidas modificaciones por el impacto que genera el propio crecimiento, y que en ocasiones se acompaña de inversiones públicas que facilitan el acceso de la población a servicios sociales esenciales y de infraestructura básica.

Sin embargo, las variaciones "a la baja" de los niveles de desigualdad medidos por el índice Gini que se registraron en los últimos quince años33, dan cuenta de cambios de mayor envergadura en la distribución del ingreso, que tienden a trascender la dinámica de expansión económica. Estudios de la CEPAL (2017) muestran el papel que desempeñaron un paquete de políticas públicas, esencialmente las de transferencias monetarias en general (contributivas y no contributivas) y las políticas laborales en la promoción de mejores condiciones de vida de la población ${ }^{4}$. En este marco se registran procesos de movilidad

3 Si bien la evolución general de esta distribución es de aumento de la igualdad, asimismo se distinguen dos períodos: uno de fuerte reducción de la desigualdad entre los años $2002-2008$ y un segundo, desde el 2010 al presente, con menores impactos. "Entre 2002 y 2008, el promedio simple [del Índice de Gini] de la región se redujo a un ritmo del 1,5\% anval y, entre 2008 y 2014, la reducción fue del 0,7\% anval. Entre 2014 y 2016, la desigualdad promedio se redujo apenas un 0,4\% al año" (CEPAL, 2017: 44).

4 Los ingresos por trabajo fueron la mayor contribución de los ingresos de los hogares pobres en el período 2002-2008 y, en ese mismo período, las transferencias fueron centrales para sostener los niveles de ingresos en determinados países (Uruguay, por ejemplo). Al respecto ver gráfica Il.6 de la página 98 de CEPAL 2017. 
social que propician que amplios sectores sociales migraran de los estratos pobres hacia los medios bajos y que simultáneamente, los grupos medios no sólo se consolidaran, sino que incorporaran a nuevos segmentos socioeconómicos5.

Para lograr tal efecto es fundamental el desarrollo de medidas públicas redistributivas, en ese sentido, algunos estudios consideran que:

Si bien en algunos períodos, en particular los de gran crecimiento, el incremento general del ingreso ha impulsado la reducción de la pobreza, las políticas que favorecen el crecimiento del ingreso de los más pobres son esenciales para continuar disminuyendo las situaciones de carencia o evitar retrocesos en este ámbito (CEPAL, 2017: 97).

La expansión de una serie de políticas sociales, como se detallará más adelante, tuvo una clara expresión en los aumentos del gasto público social del continente, generando expectativas entre analistas especializados en estos temas, que un conjunto de países latinoamericanos, especialmente los que contaban con legados universalistas de protección, tenían posibilidades de completar sus arquitecturas de bienestar, (MARTíNEZ FRANZONI; SÁNCHEZ-ANCOCHEA, 2014).

Gráfica 2. América Latina (21 países): evolución del gasto público social como porcentaje del PIB del 2000 al 2015.

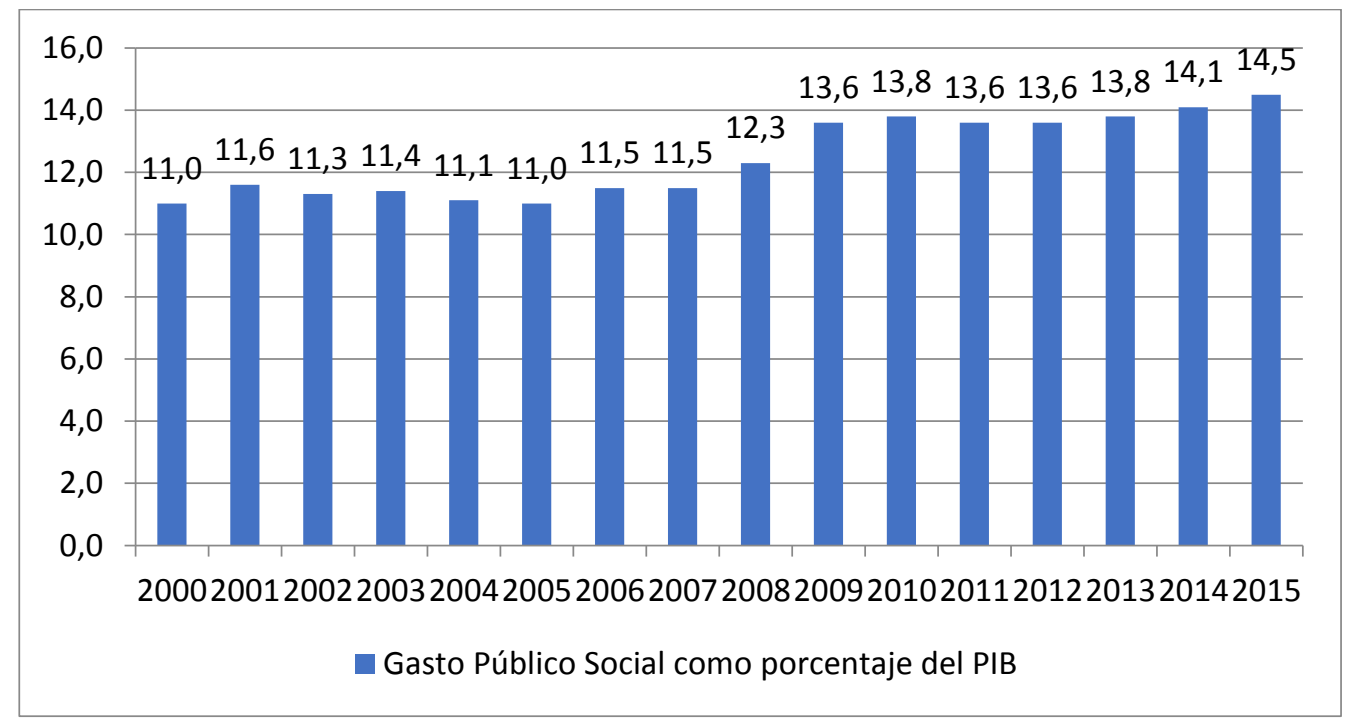

Fuente: Comisión Económica para América Latina y el Caribe - CEPAL (2016).

Las tendencias a la universalización de la intervención pública se tornaron evidentes en diversas arenas de protección, vía la incorporación a la seguridad social de grupos

5 Este proceso se puede identificar en CEPAL, 2017. 
poblacionales nuevos o históricamente excluidos o a través de las mejoras en la provisión de bienes públicos, modificaciones de los instrumentos y de la organización de la oferta pública instituida (MARTÍNEZ FRANZONI; SÁNCHEZ-ANCOCHEA, 2016).

En este marco, se especulaba que América Latina tenía la oportunidad económica (crecimiento) y política (estabilidad democrática y gobiernos de izquierda o progresistas) de recrear sus sistemas de protección, bajo parámetros de desarrollo diferentes a los que habilitaron la instalación de los bondadosos esquemas de bienestar europeos.

Cabe anotar que desde la década del ochenta se han instrumentado reformas sanitarias tendientes a la conformación de sistemas nacionales de salud, sin embargo, en los últimos años se han procesado algunos cambios de interés. En particular interesa destacar la introducción de reformulaciones sectoriales específicas que reposicionan al estado en esta arena de política (tales los casos del Plan AUGE en Chile o la reforma de salud de Uruguay). No obstante, es de resaltar el avance en términos de equidad en esta arena de política pública, pero aún persisten importantes desigualdades respecto a la calidad, eficiencia y fragmentación interna del sistema (MESA LAGO, 2007).

Complementariamente a estos cambios sectoriales, se identifican tímidas modificaciones en los esquemas de seguridad social, esencialmente los de pensiones y jubilaciones, los que fueron objeto fuertes revisiones pro-mercado en los años '9o, poniendo en evidencia la configuración de un legado liberal en este sector. La excepción en esta línea de acción fue Argentina, que estatizó su esquema previsional, mejorando el acceso a este tipo de prestaciones (DANANI, 2012).

No hay lugar a dudas, que los cambios introducidos en el sector laboral y en el asistencial fueron los más significativos en el período y tuvieron mayor incidencia en la mejoría de la situación social de los países de la región, debido a que el primero moderó el conflicto capital-trabajo, y la estabilización de las políticas de asistencia pusieron de manifiesto la responsabilidad del Estado de las situaciones de vulnerabilidad social. Por esta razón, en la siguiente sección se expondrán con cierto detalle las modificaciones sustantivas impulsadas en estas dos arenas de políticas sociales.

b) Las principales arenas de políticas sociales sujetas a cambios: asistencia y trabajo

En el contexto de crecimiento económico reseñado previamente, se implementaron modificaciones en materia laboral que llevaron a una mejora generalizada de las 
condiciones de vida de diferentes grupos de población. Si bien en los primeros años del nuevo siglo, no parecieron impulsarse grandes reformas laborales, a excepción de la argentina $(2001,2004)$ y la uruguaya $(2005)$, se evidenciaron avances en derechos laborales colectivos y esencialmente individuales. Pero más allá del tipo y envergadura de las reformas implementadas lo que sí es un hecho es la generalización de mejoras sectoriales de la mano con condiciones para la negociación colectiva, la evolución en la calidad del empleo y los principales indicadores en esta arena de política registraron guarismos promisorios. No obstante, estos avances en los últimos años parecen deteriorarse el estado de situación del ámbito laboral.

En relación a las principales tendencias del mercado laboral, vale la pena mencionar que en el año 2004 comenzó un período de reducción del desempleo que llevó a una caída histórica que rondó el 6\% en los años 2007 y en el 2013 y 2014 (OIT, 2013, 2017). Es de resaltar además que estos incrementos en el nivel de empleo se procesaron en sectores formales de la economía y, como se verá a continuación, con aumentos del salario mínimo. La buena performance en materia de reducción del desempleo parece revertirse en los últimos años ya que en el tercer trimestre del año 2017 se registró un incremento al 8,7 (OIT, 2017). La tendencia general de variación de la tasa de desempleo se puede observar en la siguiente gráfica, pero vale la pena aclarar que hay leves variaciones en las cifras debido a que se toman proyecciones de OIT y no los valores reales de cada país.

Gráfica 3. Evolución de la tasa de desempleo en América Latina y en Argentina, Brasil, Chile, Paraguay y Uruguay. Estimaciones de OIT.

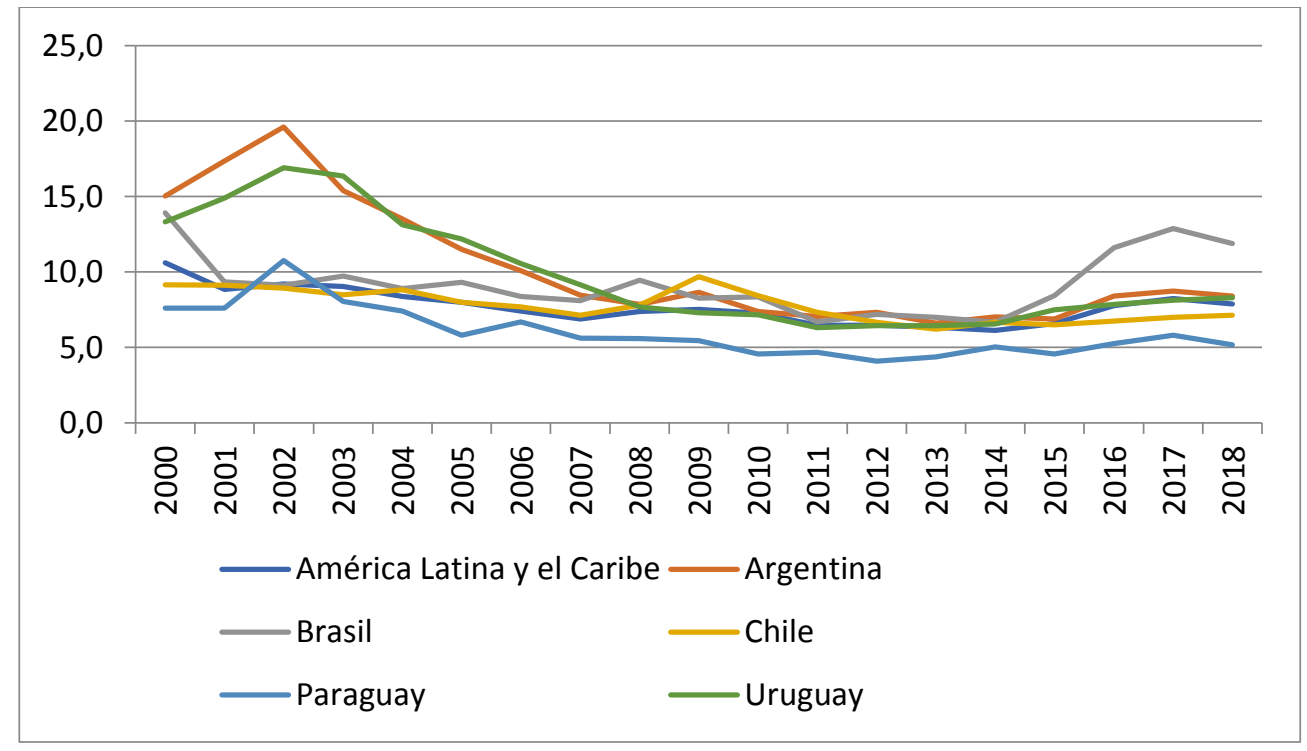

Fuente: Base de daos de OIT, www.ilo.org/global/statistics-and-databases/lang--en/index.htm 
Además de esa evolución de la tasa de desempleo hay que destacar que a lo largo de los últimos quince años han bajado los índices de informalidad laboral, aunque aún persisten niveles significativos. Para el año 2013, un $47 \%$ de los ocupados no agrícolas trabajaban en condiciones de informalidad (OIT, 2013). No obstante ello, es de resaltar que se han registrado avances importantes en el empleo formal y en particular el número de cotizantes a sistemas de pensiones en la región pasó de un 46,1 en el año 2002 a un 55,4\% en el 2011 (CEPAL, 2013). Esta tendencia de incremento del empleo formal se registra claramente para Argentina, Brasil, Chile y Uruguay.

Respecto a las cifras que ilustran la calidad del empleo en la región en los últimos dos años, existen algunas señales contradictorias que ameritarían una problematización de ese estado de situación. Por un lado aumentó la cobertura de seguridad y de seguros de salud aunque éste último lo hizo en menor medida en 2016 respecto al 2015. Por otro lado, se encienden señales de alarma ya que se registró cierto deterioro de la calidad del empleo medida por el porcentaje de trabajadores con contrato escrito de trabajo (OIT, 2017).

En este plano, cabe destacar que en el período se instrumentaron medidas laborales en pro de la regulación del mercado de empleo, promoviendo derechos colectivos (negociaciones tripartitas, reconocimiento de derechos sindicales, etc.) que provocaron aumentos de las tasas de sindicalización, esencialmente en el Cono Sur, entre 2005-2014, aunque retrocedió levemente entre 2015 y 2016 (OIT, 2017)6.

En relación a esta temática, importa señalar que la mejora en la capacidad sindical guarda una estrecha relación con el incremento del número de trabajadores cubiertos por instancias de negociación colectiva, y el aumento del porcentaje de trabajadores en este plano se constituye, indudablemente, en una mejora sustantiva en el poder de negociación de los trabajadores. En ese sentido, como se puede comprobar para los años con los que se cuenta con información, de todos los países del Cono Sur, sólo en Paraguay no se registra un aumento en este rubro.

\footnotetext{
${ }^{6}$ Conviene tomar con cautela estas cifras ya que existen incentivos indirectos a la afiliación en un conjunto de países (tales como en Argentina con las obras sociales gestionadas por las centrales sindicales con personería gremial). Con lo cual la mejora en la afiliación no da cuenta de forma precisa de la capacidad o poder sindical existente en la región.
} 
Cuadro 1. Evolución de la tasa de cobertura de la negociación colectiva

\begin{tabular}{|c|c|c|c|c|c|c|c|c|c|c|c|c|c|}
\hline & 2004 & 2005 & 2006 & 2007 & 2008 & 2009 & 2010 & 2011 & 2012 & 2013 & 2014 & 2015 & 2016 \\
\hline Argentina & $s / d$ & $s / d$ & $s / d$ & $s / d$ & 50,9 & 50,6 & 52,4 & 51,2 & 50,5 & 51,5 & 51 & 52,9 & 51,8 \\
\hline Brasil & $s / d$ & $s / d$ & $s / d$ & $s / d$ & $s / d$ & 58,8 & $s / d$ & 63,1 & 63,8 & 65,7 & 70,5 & $s / d$ & $s / d$ \\
\hline Chile & $s / d$ & $s / d$ & $s / d$ & $s / d$ & $s / d$ & 26,6 & 25 & 15,6 & 16,6 & 17,3 & 18,1 & 17,6 & 17,9 \\
\hline Paraguay & $s / d$ & $s / d$ & $s / d$ & $s / d$ & $s / d$ & $s / d$ & $s / d$ & 0,8 & 0,7 & 0,7 & 0,7 & 0,7 & $s / d$ \\
\hline Uruguay & $s / d$ & $s / d$ & $s / d$ & 89 & 92,3 & 95,6 & 98,5 & 97,9 & 91,9 & 95,2 & 94,8 & 94,7 & 94,6 \\
\hline
\end{tabular}

Fuente: Base de daos de OIT, www.ilo.org/global/statistics-and-databases/lang--en/index.htm

Pero no sólo se constaron mejoras en los derechos colectivos, sino que también se evidenciaron importantes mejoras de derechos laborales individuales que se plasmaron en el crecimiento del salario mínimo en la mayoría de los países de la región, cuyo incremento promedio entre 2005-2015 se ubicó en un 3,6\% real al año. (OIT, 2017). No obstante ello, existen notorias diferencias entre los países, ya que en algunos el aumento ha sido menor al $25 \%$ mientras que para otros ha crecido más del $50 \%$.

Gráfica 4. América Latina: variación de los salarios mínimos reales según subregiones. 20052015 (Año 2005=100)

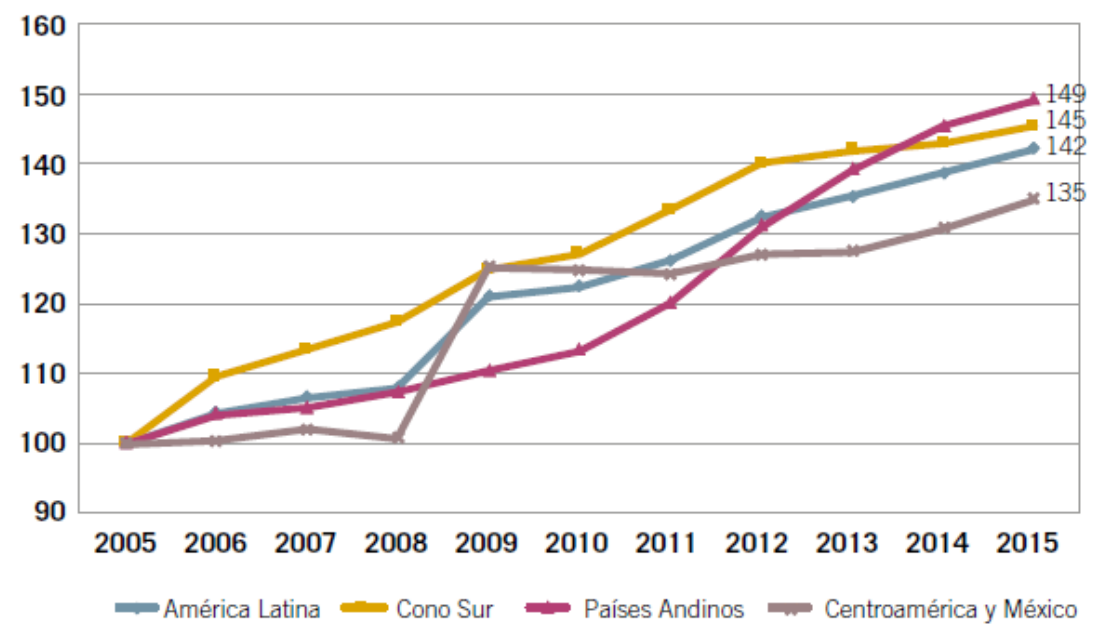

Fuente: (OIT, 2017).

Las políticas de aumento del salario mínimo han desempeñado un papel fundamental en la reducción de la desigualdad en la región y esta reducción adquiere destaque en algunos de los países del Cono Sur, en particular en Brasil y Argentina como se puede apreciar en el cuadro que sigue. 
Cuadro 2: América Latina (4 países): Impactos distributivos del salario mínimo

\begin{tabular}{|c|l|l|}
\hline \multirow{2}{*}{ Argentina (2003-2012) } & Percentil 9o/percentil 10 & $72 \%$ \\
\cline { 2 - 3 } Brasil (2003-2011) & Gini & $32 \%$ \\
\hline \multirow{2}{*}{ Chile } & Percentil 9o/percentil 10 & $189 \%$ \\
\cline { 2 - 3 } & Gini & $84 \%$ \\
\hline \multirow{2}{*}{ Uruguay } & Percentil 9o/percentil 10 & $16 \%$ \\
\cline { 2 - 3 } & Gini & $6 \%$ \\
\hline & Percentil 9o/percentil 10 & $48 \%$ \\
\cline { 2 - 3 } & Gini & $7 \%$ \\
\hline
\end{tabular}

Fuente: (CEPAL, 2015).

Como se ha podido apreciar de acuerdo al conjunto de cifras presentadas, que América Latina en general y las naciones sudamericanas en particular, han mostrado una mejora en el campo laboral, relativo a: descenso de desempleo; mejoras en la calidad del empleo; incrementos en la evolución del salario real y, el crecimiento de la proporción de trabajadores cubiertos por mecanismos de negociación colectiva.

Otro sector novedoso en los años 2000 fue el de la asistencia social, en la medida que se constituyó en un campo de intervención pública institucionalizado y con encuadres organizativos propios. Importa plantear que desde fines de los años '8o hasta inicio del nuevo siglo América Latina se convirtió en un escenario privilegiado de experimentación de programas provisorios de combate a la pobreza. Sin embargo, comenzaron a registrarse cambios en la operativa de ese universo de prestaciones, en la medida que tendieron a estabilizarse y simultáneamente se expandieron en casi todas las naciones de la región a través de los llamados Programas de Transferencias Condicionadas (PTC)7 de Renta.

La orientación de superación de la pobreza que tienen este tipo de iniciativas públicas posibilitó la incorporación de amplios sectores de población tradicionalmente excluidos a mecanismos instituidos de protección social. Las condicionalidades establecidas en el diseño de programas, relativas a la obligatoriedad de controles sanitarios y de asistencia a los centros de enseñanza pública según características de los beneficiarios, así como los paquetes de bienes complementarios que acompañaron una proporción de los PTC, facilitó el acceso a un conjunto de servicios sociales básicos y mejoró la articulación intersectorial de la gestión pública.

\footnotetext{
7 En el año 2015 existían 30 programas de transferencias con diseño similar en América Latina y el Caribe.
} 
Paralelamente, la instrumentación de estos PTC ha impactado favorablemente en la reducción de las estrategias clientelares para la distribución de beneficios sociales que caracterizó históricamente a la región. En particular, la adopción de instrumentos técnicos en la selección de las personas u hogares beneficiarios, así como la mejora en los registros y en los sistemas de información posibilitó una ejecución más técnica y con menos injerencia política en el acceso a los bienes públicos (CECCHINI y ATUESTA, 2017).

Estas iniciativas, pese a ser focalizadas en grupos poblacionales en situación de pobreza, pasaron a tener una cobertura de magnitud significativa y además, como se señaló previamente, tendieron a institucionalizarse vía el financiamiento con recursos de los presupuestos nacionales.

En la gráfica que se presenta a continuación se evidencia un notable incremento de hogares beneficiarios de PTC en América Latina en el período 1996 al 2016. Si bien no se aprecia una evolución homogénea de cobertura en los países de la región, sí se constata un aumento de beneficiarios, y en consecuencia cierto grado de importancia política a la atención de esos sectores. Esa tendencia incremental en el porcentaje de hogares incorporados a PTC se constata hasta el 2014 a partir de ese año comienza a bajar.

Cabe resaltar que, en Argentina, Brasil y Uruguay el número de personas que viven en hogares beneficiarios es igual a la población en condiciones de pobreza.

Gráfica 5. América Latina y el Caribe: Hogares que participan en PTC, 1996 - 2016 (en porcentaje del número total de hogares)

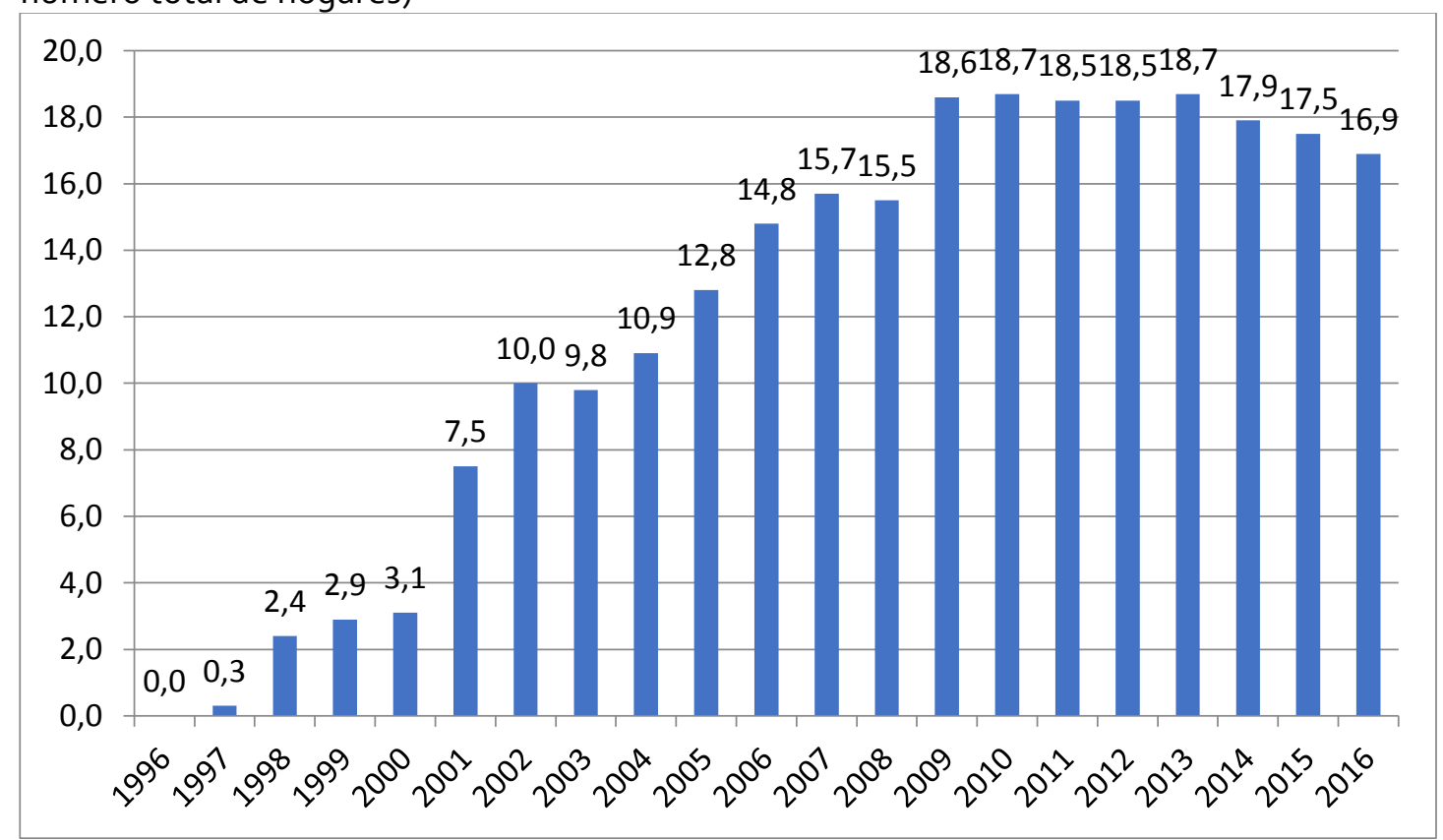

Fuente: Cecchini y Atuesta, 2017. 
Pese a tener una cobertura significativa los PTC insumen un bajo nivel de gasto público que oscilaba, para el año 2015, entre 0,01 a un casi 0,7 del PIB. En ese panorama de baja inversión pública en estos programas, se evidencia cierto nivel de variabilidad interna, ya que en algunos casos los recursos financieros utilizados son extremadamente reducidos (básicamente en el Caribe), a diferencia de otras regiones como el Cono Sur donde el gasto promedio se ubicaba 0,4 por ciento del PIB en el año 2015, y sólo Chile se distancia de ese parámetro.

Gráfica 6. América Latina y el Caribe: Inversión de los PTC, según países, alrededor de 2015 (en porcentajes del PIB).

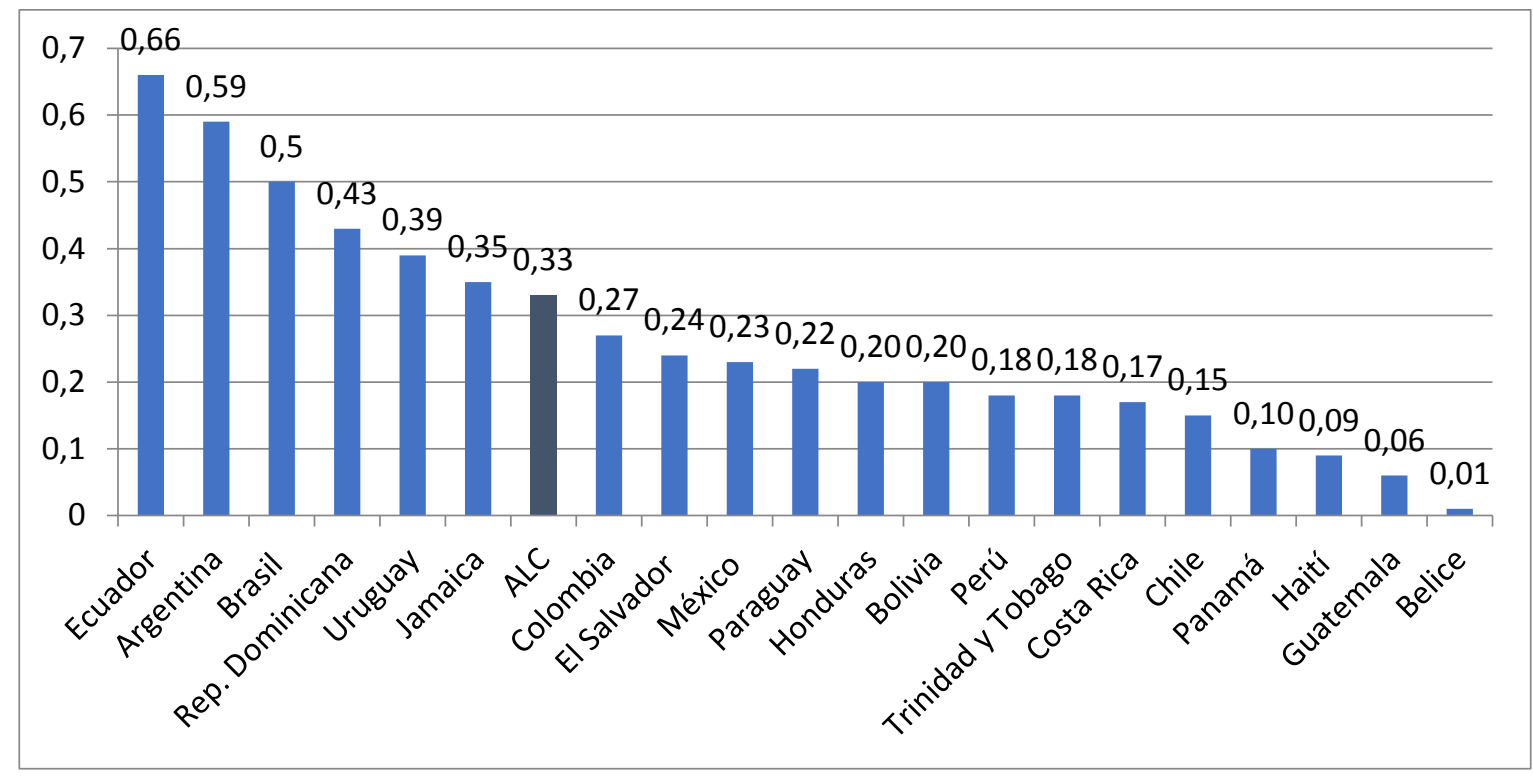

Fuente: (CECCHINI y ATUESTA, 2017).

A continuación, se detallan las propuestas más destacadas de PTC con permanencia hasta el presente en Sudamérica. Corresponde destacar que este universo particular de iniciativas sociales presentan una serie de características comunes tales como:

la regularidad y la garantía de tiempo de las prestaciones en efectivo. Están dirigidos a hogares pobres o extremadamente pobres - por lo que se adoptan criterios de focalización geográfica y por hogares-y las transferencias se entregan por lo general a las madres (CECCHINI y ATUESTA, 2017, p. 16). 
Cuadro 3. Principales Programas de Transferencias Condicionadas de Renta en Argentina, Brasil Chile, Paraguay y Uruguay

\begin{tabular}{|c|l|c|}
\hline \multicolumn{1}{|c|}{ País } & \multicolumn{1}{|c|}{ Nombre } & Año de Inicio \\
\hline \multirow{2}{*}{ Argentina } & Asignación Universal por Hijo & 2009 \\
\cline { 2 - 3 } & Bolsa Familia & 2003 \\
\cline { 2 - 3 } & Bolsa Verde & 2011 \\
\cline { 2 - 3 } & Erradicação do Trabalho Infantil & 1996 \\
\hline \multirow{2}{*}{ Chile } & Chile Solidario (CHS) & 2002 \\
\cline { 2 - 3 } & Subsistema de Seguridades y Oportunidades (Ingreso Ético Familiar) & 2012 \\
\hline \multirow{2}{*}{ Paraguay } & Tekoporã & 2005 \\
\cline { 2 - 3 } & Abrazo & 2005 \\
\hline \multirow{2}{*}{ Uruguay } & Plan de Equidad/Asignaciones Familiares (AFAM - PE) & 2008 \\
\cline { 2 - 3 } & Tarjeta Uruguay Social & 2006 \\
\hline
\end{tabular}

Fuente: Elaboración propia en base a documentos, páginas electrónicas oficiales de los países y Cecchini y Atuesta (2017).

En síntesis, para cerrar este ítem corresponde plantear que grupo de iniciativas asistenciales renovaron la oferta pública social en la mayoría de los países pese a que no tuvieron fuertes impactos para reducir la desigualdad del continente (Valencia, 2012) No obstante la limitada incidencia socioeconómica de esas estrategias de acción, se evidencia que han tenido impactos políticos e institucionales, relativos la reincorporación entre las responsabilidades estatales del tratamiento de las situaciones de vulnerabilidad social (MIDAGLIA y CASTILLO, 2014).

a) Algunas explicaciones sobre la expansión regional de la protección social

Más allá del mencionado crecimiento económico registrado en el período, múltiples estudios sobre América Latina han dado cuenta de un conjunto de variables políticas que favorecieron el despliegue de la intervención pública en materia social.

Asumiendo estabilidad democrática, con proyecciones de ciclos electorales que habilitan a la rotación de los gobiernos, algunos analistas consideran que la competencia política por el voto de la población vulnerable (outsiders) y la movilización de los sectores populares son los principales factores explicativos del crecimiento y consolidación de las políticas de asistencia, esencialmente, las transferencias monetarias condicionadas dirigidas a sectores sociales en condiciones de pobreza extrema y moderada, (Garay, 2010:2). La 
relación competencia electoral y promoción de programas sociales se encuentra mediatizada por las preferencias de las bases políticas de los partidos en disputa, dando lugar a esquemas de protección diferenciales, más o menos restrictivos o bondadosos en el acceso y en la distribución los bienes públicos. De esta manera, los partidos conservadores serán favorables a sistemas de asistencia social limitados en beneficios y cobertura (Garay, 2010: 197), a diferencia de las colectividades políticas de izquierda que reclutan apoyos, entre otros, en los sectores sociales calificados de populares.

Por su parte, Huber y Stephens también reconocen la incidencia que tiene la competencia política, en particular entre fuerzas de orientación de izquierda con otras más liberales en el incremento y consolidación de protecciones sociales, no sólo asistenciales sino aquellas de opción redistributiva (Huber y Stephens, 2012: 3)

De acuerdo con este tipo de argumentos y a la vez incluyendo nuevas variables políticas explicativas sobre la ampliación de los esquemas de bienestar, se encuentran los estudios sobre tipos de izquierdas políticas y reformas sociales, en particular las laborales. En línea con la aplicación de la teoría de recursos de poder (Korpi, 1985) en la consideración de las mejoras de los parámetros distributivos, se constata que los partidos de izquierda de masa con fuerte vínculos con los sindicatos de acuerdo a la tipología de Levitsky y Roberts (2011), así como otros modelos de organización política (populismos) han sido impulsores de reformas laborales de envergadura (Cook y Bazler, 2013; Carneiro, 2017). Si bien cada uno de los análisis de referencia centran la atención en aspectos específicos de las revisiones de las intervenciones públicas enmarcadas en el mercado empleo, tomados en conjunto ponen en evidencia los variados formatos de intermediación de intereses entre las fuerzas políticas de izquierda y los sindicatos a favor de protecciones sociales.

En síntesis, la dinámica democrática en clave de competencia política, la movilización popular y la articulación entre fuerzas políticas de orientación de izquierda y sindicatos, se consideran los factores políticos más relevantes de la expansión de bienestar regional.

b) Revisiones y retrocesos de la protección regional

Como ya se mencionó en ítems anteriores, el cambio de siglo trajo novedades políticas en Latinoamérica, en la medida que partidos de orientación de izquierda o progresistas, con diversa trayectoria y características organizacionales se transformaron en 
gobiernos en una proporción de las naciones desde 2001 al 2016, (aunque en algunos países aún se mantienen).

En este inédito escenario regional, se procesaron simultáneamente dos tipos de desarrollo: por una parte, el económico atendiendo lo niveles sostenidos de crecimiento hasta mediados de 2013, producto del boom en los precios internacionales de las commodities que se constituían en el $60 \%$ del valor de las exportaciones del continente (Grijalva, 2014) y por otra, dosis significativas de desarrollo social a través de la extensión de los esquemas de protección vigentes.

En el año 2013 comenzaron a evidenciarse claramente signos de desaceleración económica, sin embargo, las perspectivas analíticas de la época se mantuvieron relativamente optimistas, ya que se consideraba que el patrón de acumulación podía ajustarse vía nuevos tratados comerciales o revisiones de la pauta de inserción internacional, y a la vez los robustecidos sistemas de bienestar nacionales se transformarían en sí mismos en frenos ante los intentos radicales de desarticularlos.

Los analistas hipotetizaban que era plausible una rotación democrática de las fuerzas políticas gobernantes, donde las izquierdas perderían espacios de poder institucional a favor de los partidos de opción más liberal o conservadora, con fuerte apoyo de los sectores socioeconómicos medios y altos, lo que efectivamente ocurrió. También se planteaba, que esas nuevas administraciones políticas llevarian a cabo revisiones de los esquemas de protección en un contexto socioeconómico diferente del que se produjo la ampliación de bienestar

En este sentido, Filgueira (2013) entendía que en la definición de las estrategias de recorte de la provisión de bienes sociales operarían factores sociopolíticos que restringirían los márgenes de maniobra para impulsar cambios significativos. De esta manera, consideraba que la ciudadanía en su conjunto, y especialmente los estratos pobres y medios con su heterogeneidad interna, habían adquirido expectativas por mejores condiciones de vida, y restringirlas en un escenario con dificultades económicas, pero donde se conservan ámbitos de negociación y movilización social, tendería a generar altos costos políticos. Estas interpretaciones parecían corresponderse con la realidad, más aún cuando la población tenía como referencia inmediata un contexto de bonanza económica y mejoras en el bienestar que habían caracterizado al continente en los últimos años.

También resultaba pertinente aplicar la visión de Garay (2010) sobre la expansión de 
políticas sociales, con los cuidados necesarios, para una etapa de recesión económica y con gobiernos conservadores. En este marco parecía plausible esperar que, los recortes de las intervenciones públicas si bien responderían a las expectativas de las bases electorales de los nuevos partidos gobernantes (clases medias y altas), su magnitud debía tener en cuenta el horizonte de las elecciones nacionales futuras. Es decir, las reformulaciones de las protecciones con tendencia a la restricción, tendrían que sopesar en los cálculos políticos la necesidad de apoyo electoral, incluyendo los grupos sociales más desfavorecidos, para mantenerse y proyectarse en el poder.

Bajo parámetros históricos diferentes, nuevamente surgen asociaciones analíticas similares a las realizadas en los años '9o entre democracia y reforma socioeconómica promercado, poniendo de manifiesto que la vigencia de ámbitos de competencia política no son favorables para impulsar reducciones en las protecciones públicas en ausencia de coyunturas críticas (graves crisis económicas, catástrofes internacionales, etc.) que alteran los habituales canales institucionales de tramitación de demandas sociales (Haggard y Kaufman, 1992; Acuña y Smith, 1994).

Sin embargo, esas predicciones no parecieron comprobarse plenamente, en algunos de los países constitutivos del Cono Sur (Brasil y Paraguay), especialmente en la nación brasileña, que tiene una importante incidencia económica y política en América Latina. En ese país se impulsaron severos recortes del gasto público y una reforma laboral que supuso importantes limitaciones de los derechos colectivos e individuales de los trabajadores. Cabe anotar, que esas reformulaciones hacia políticas públicas restrictivas, se llevaron a cabo en un sistema democrático debilitado, ya sea por los escándalos de corrupción política y la sustitución del presidente, a través de mecanismos legales "impeachment", alterando la orientación y la correlación de fuerzas políticas que había surgido de las elecciones nacionales.

El estado de situación política planteado parece ser indicativo que el presupuesto en el que descansaban el conjunto de hipótesis mencionadas sobre el futuro del bienestar regional, relativo a que la democracia estaba afianzada en estas latitudes no parece comprobarse, al menos en los casos arriba señalados, con especial atención en Brasil debido a su trascendencia regional. Recurriendo a distintas definiciones de Democracia, desde las clásicas que enfatizan la primacía de las reglas de juego como garantía de su funcionamiento en contextos económicos y políticos con cierto grado de dispersión de 
poder (Dahl, 1992), hasta las minimalistas que la consideran un "método" para generar gobiernos o un arreglo institucional de toma de decisiones a través del voto ciudadano (Schumpeter, 1984), los acontecimientos políticos que se procesaron en el mayor país del Cono Sur no parecen ajustarse plenamente a esos parámetros. Entre las acciones críticas que cuestionan el funcionamiento su sistema político figura la aplicación de mecanismos de excepción para la sustitución de representantes -"impeachment"-, los que si bien forman parte del set de instrumentos legales disponibles para procesar ajustes, alteran las preferencias ciudadanas surgidas de las urnas y en algún sentido debilitan el contralor efectivo que ejercen las elecciones (Traversa y Carneiro, 2017).

Además, en esos peculiares escenarios políticos, se tiende a desarticular los canales de relación y comunicación entre el gobierno y los actores colectivos, fundamentalmente los favorables a la distribución económica, y con ello la agenda pública aprobada y legitimada por la población en su conjunto. Como bien planteaba Geddes (1994) en sus análisis sobre la implantación de políticas de orientación al mercado en algunos países latinoamericanos, si bien la movilización popular no logró detener los procesos de reformulación socioeconómica, al menos puso de manifiesto el descontento y la resistencia ciudadana y cabría agregar que, en ciertos casos, moderó los paquetes de reforma admitidos.

En este nuevo contexto regional, importa reiterar la influencia que ejerce Brasil, y en consecuencia los cambios que impulse en sus políticas económicas, comerciales, de inserción internacional, así como de protección social, en particular las laborales, tienden a condicionar, en alguna medida, a las naciones vecinas.

Si bien, la debilidad democrática del "gigante" regional, impide que se contrasten cabalmente en ese país las hipótesis anunciadas sobre la moderación reformista para un período como el actual, de signo económico desfavorable y con administraciones políticas en su mayoría de orientación liberal, se torna necesario formular explicaciones alternativas que permitan incorporar otros casos de América del Sur, esencialmente, Argentina y Chile.

En este marco, se plantea incluir con mayor detalle en los análisis de las pautas de recorte de las prestaciones sociales, la estructura actual de los actores sociales como los sindicatos, y considerar su grado de fragmentación interna, las estrategias adoptadas de defensa de las protecciones obtenidas y las articulaciones establecidas con los nuevos gobiernos y las élites económicas. Se torna plausible suponer, que en un contexto con 
dificultades económicas, una parte de las explicaciones sobre los ajustes del bienestar social, al igual que en la etapa de crecimiento, son de naturaleza política. En este marco, se tendría que considerar con especial atención, el tipo de actores colectivos que enfrentan estas situaciones, atendiendo sus demandas, así como las posiciones que asumen en conjunto o algunas de agrupaciones, sobre la distribución de los costos sociales del recorte de las prestaciones públicas. Seguramente, este campo de factores políticos, permite profundizar la comprensión sobre distintos escenarios regionales de recorte de las protecciones sociales.

No hay lugar a duda, que la coalición pro-distribución que dominó la primera década del siglo XXI se encuentra gravemente debilitada, pero simultáneamente no resulta evidente la estabilidad de las bases socioeconómicas y políticas de los nuevos gobiernos de la región.

\section{Consideraciones Finales}

En los últimos quince años América Latina registró significativos avances en los indicadores sociales y en sus esquemas de protección pública, de la mano del crecimiento económico y de la estabilidad democrática.

No hay lugar a duda, que la mejora en la situación socioeconómica regional tuvo incidencia directa en la moderación de las situaciones de pobreza y vulnerabilidad, sobre todo en las denominadas "áreas blandas" de desarrollo, las que se activan con mínimas inversiones públicas.

Más allá de la operativa económica, existe un amplio consenso académico de la importancia que han tenido los factores políticos para tramitar y estabilizar algunos de los avances sociales a través de políticas públicas. La competencia política entre partidos de distinta orientación (Huber y Stephen 2010; Garay, 2010); la movilización de los sectores populares, en su mayoría insertos en el mercado informal de trabajo (Garay, 2010) y la articulación de los actores colectivos pro-distribución (sindicatos) con fuerzas políticas de orientación de izquierda o progresistas (Carneiro, 2017), favorecieron la promoción de un conjunto de políticas laborales y asistenciales que tendieron a ampliar los esquemas nacionales de seguridad social.

El escenario de desaceleración del crecimiento como el actual, se asiste a un 
debilitamiento de la gravitación de los factores políticos que aseguraron dosis de distribución y de protección social.

Corresponde indagar, ¿qué sucedió en Latinoamérica y en particular en el Cono Sur, para que se procese un rápido recorte de las inversiones sociales, las regulaciones y los beneficios laborales?

La respuesta más plausible a esta pregunta de coyuntura, que tendería a explicar este rápido cambio rumbo en las principales políticas de bienestar, radica que la democracia, en tanto precondición para tramitar el conflicto distributivo, no gozaba de tan "buena salud", esencialmente en algunos países de la región. Brasil, que tiene incidencia en otras naciones regionales.

En este escenario, el tipo, la fortaleza y el posicionamiento de los actores colectivos con capacidad de moderar las nuevas reformas sociales impulsadas, adquieren relevancia y permiten comprender las estrategias de ajuste promovidas en el conjunto de los países del Cono Sur.

Los nuevos gobiernos regionales, en su mayoría calificados de derecha dada su orientación favorable a políticas pro-mercado, se han encontrado hasta el momento con escasas resistencia para tramitar los recortes de las intervenciones públicas. Sus bases electorales reflejan las expectativas y las demandas de las clases medias que generan opinión pública e inciden en la agenda política.

La coalición pro-distribución que predominó en los años anteriores parece que se ha agotado. No obstante, no resulta clara la fortaleza de las bases de respaldo socioeconómicos de las actuales administraciones políticas democráticas a la vez, que no se descarta una posible la activación de las organizaciones sociales.

El rumbo político que puede tomar la región es incierto y más aún en las arenas de políticas públicas, sujetas en el presente a reformulaciones significativas de opción liberal.

\section{Bibliografia}

Acuña Carlos y Smith William, (1994); "The Political Economy of Structural Adjustement: The Logic of Support and Opposition to Neoliberal Reform", in Latin American Political Economy in the Age of Neoliberal Reform, org. Smith W., Acuña C. and Gamarra E. Ed. Transaction Publishers USA and London.

Arditi, Benjamín, (2009): El giro a la izquierda en América Latina: ¿una política post-liberal? Ciências Sociais Unisinos 45(3):232-246, setembro/dezembro 2009. Brasil: Unisinos. 
Barba, Carlos (2016): "Las Transferencias Monetarias en América Latina: Tres Oleadas y una Tipología", ponencia presentada en Welfare States, Labour Rights and Basic Income in Latin America, International workshop organized by the Comparative Research Programme on Poverty-CROP (ISSC/UiB) and the Catholic University of Salvador, Brazil.

Carneiro, Fabricio, (2017): Desagregando reformas: sindicatos y reformas laborales en izquierdas moderadas. Tesis de Maestría, Universidad Torcuato Di Tella. Argentina: Universidad Torcuato Di Tella.

Cecchini, Simone y Atuesta, (2017): Programas de transferencias condicionadas en América Latina y el Caribe. Tendencias de cobertura e inversion. Serie Políticas Sociales No 224. Santiago de Chile: CEPAL.

CEPAL (2017): Panorama Social de América Latina, 2017. Santiago de Chile: Comisión Económica para América Latina (CEPAL).

CEPAL (2016): Panorama Social de América Latina, 2016. Santiago de Chile: Comisión Económica para América Latina (CEPAL).

CEPAL (2015): Salario mínimo en la agenda de Desarrollo de América Latina. Presentación realizada por Antonio Prado Secretario Ejecutivo Adjunto en el Seminario Internacional sobre Salario Mínimo. Fundación Friedrich Ebert Dieese. Belo Horizonte, 9 de noviembre de 2015 .

CEPAL (2013): Panorama Social de América Latina, 2013. Santiago de Chile: Comisión Económica para América Latina (CEPAL).

Cook, Maria Lorena and Bazler Joseph, (2013): Bringing Unions Back In: Labour and Left Governments in Latin America. Working Papers 4. New York: Cornell University ILR School.

Dahl, Robert (1992): La democracia y sus críticos. España: Editorial PAIDOS IBERICA.

Danani, C. (2013). "El Sistema de Protección Social Argentino entre 2002 y 2013: Buscando el modelo que nunca tuvo". En Revista Uruguaya de Ciencia Política No 22, No2, 2013 Los cambios en los sistemas de Bienestar latinoamericanos: avances y desafíos de la protección social. Montevideo: Instituto de Ciencia Política - Facultad de Ciencias Sociales. ISSN: 0797 9789. ISSN 168-499X (en línea).

Dos Santos, W., (1987): Cidadanía e Justicia. Río de Janeiro: Ed. Campus.

Filgueira, Fernando, (2013): "Los Regímenes de Bienestar en el Ocaso de la Modernización Conservadora: Posibilidades y Límites de la Ciudadanía Social en América Latina". Revista Uruguaya de Ciencia Política - Vol. $22 \mathrm{~N}^{\circ} 2$ - ICP - Montevideo. Montevideo: Departamento de Ciencia Política.

Filgueira, Fernando, (2005): "Welfare and Democracy in Latin America: The Development, Crises and Aftermath of Universal, Dual and Exclusionary Social States". Draft Working Paper, Geneva: UNRISD.

Filgueira, Fernando, (1998): "El nuevo modelo de prestaciones sociales en América Latina; 
residualismo y ciudadanía estratificada". En Brian Roberts (ed.). Ciudadanía y política social. San José: FLACSO/SSRC., pp.71-116.

Filgueira, Carlos, (1997): "Introducción", Desafíos de la Seguridad Social; comp. C. Filgueira, C. Midaglia y J. Petersen-Thumser. Programa Latinoamericano de Políticas Sociales, CIESU, DSE. Montevideo: Ed. Trilce.

Flora, Peter \& Alber, Jens, (1981): "Modernization, Democratization and the Development of Welfare States in Western Europe". En P. Flora y A. J. Heidenheimer (eds.). The Development of Welfare States in Europe and America. New Jersey: Transaction Publishers New Brunswick.

Garay, María Candelaria, (2010): Including Outsiders: Social Policy Expansion in Latin America. Theses and Dissertation, by PhD Political Science. California: University of California.

Geddes, Bárbara, (1994); "Challenging the Conventional Wisdom", in Journal of Democracy; vol. 5, No 4i . Ed. Johns Hopkins University.

Gough, lan y Wood, Geof, (2004): "Introduction", Insecurity and Welfare Regimes in Asia, Africa and Latin America. Social Policy in Development Contexts. Cambridge: Cambridge University Press.

Grijalva, Diego, (2014). El fin del súper ciclo de los Commodities y su impacto en América Latina. Ed.Instituto de Econonía de la USFQ, No 48, año 7. Koyuntura.

http://www.usfq.edu.ec/publicaciones/koyuntura/Documents/koyuntura_2014-48.pdf

Haggard Stephan and Kaufman Robert, (1992); "Economic Adjustment and the Prospects for Democracy", in The Politics of Economic Adjustment. International Constraints, Distributive Conflicts, and the State, org.Haggard S. and Kaufman R. Ed. Princeton University, New Jersey.

Huber, Evelyne and Stephens, John, (2012): Democracy and the Left. Social Policy and Inequality in Latin America. Chicago: The University of Chicago Press.

Korpi, Walter, (1985): "Power Resources Approach vs. Action and Conflict: On Causal and Intentional Explanations in the Study of Power". Sociological Theory, Vol. 3 No 2, pp. 31-45. USA: American Sociological Association (ASA).

Kurtz Marcus J, (2004): The Dilemmas of democracy in the open Economy Lessons from Latin America. World Politics, Volume 56, Number 2, pp.262-302.

Levitsky, Steven, y Kenneth M. Roberts, (2011): The Resurgence of the Latin American Left. USA: John Hopkins University Press.

Marshall, T.H. 1950. Citizenship and social Class. Cambridge: Cambridge University Press.

Martínez Franzoni, Juliana y Sánchez Ancochea, Diego (2016): The Quest for Universal Social Policy in the South. Actors, Ideas and Architectures. Cambridge: Cambridge University Press. 
Martínez Franzoni, Juliana y Sánchez Ancochea, Diego (2014): "Should Policy Aim at Having All People on the Same Boat? The Definition, Relevance and Challenges of Universalism in Latin America", Working Paper Series 70, Berlin: International Research Network on Interdependent Inequalities in Latin America. Disponible en: desiguALdades.net.

Mesa-Lago, Carmelo, (2007): Reassembling Social Security. A surrey of pensions and healthcare reforms in Latin America. New York: Oxford University Press.

Mesa-Lago, Carmelo, (2001): "Structural reform of social security pensions in Latin America: Models, characteristics, results and conclusions", International Social Security Review. Vol. 54, 4, pp. 67-92.

Mesa-Lago, Carmelo, (1986): "Seguridad social y desarrollo en América Latina", Revista de la CEPAL, No 28, Santiago, pp. 131-146. Santiago de Chile: Comisión Económica para América Latina y el Caribe (CEPAL).

Mesa-Lago, Carmelo, (1978): Social Security in Latin America: Pressure Groups, Stratification and Inequality. Pittsburgh: University of Pittsburg Press

Midaglia, Carmen y Antía, Florencia, (2017): Bienestar y Protección Social en América Latina. Abordajes Conceptuales y Metodológicos para el MERCOSUR. Paraguay: Instituto Social del MERCOSUR.

Midaglia, Carmen y Castillo, Marcelo (2014): "Cuando baja la marea: los cambios de las protecciones sociales en América Latina en el siglo XXI". Horizontes LatinoAmericanos Revista de Humanidades e Ciências Sociais do Mercosul Educacional./Fundação Joaquim Nabuco - Vol. 3, No. 1 (Dic. 2014), PP: 13-36. Recife: Editora Massangana, Fundação Joaquim Nabuco.

Midaglia, Carmen y Castillo, Marcelo (2009): "Reforma social y sistema de protección: argumentos para la direccionalidad política de las intervenciones públicas" en Mas allá de la pobreza. Regímenes de Bienestar en Europa, Asia y América, Comp. Carlos Barba, Gerardo Ordóñez y Enrique Valencia. Guadalajara: Universidad de Guadalajara-El Colegio de la Frontera Norte.

Ocampo, J. A. (2011) Seis décadas de debates económicos latinoamericanos, Disponible en: http://policydialogue.org/files/events/SEGIB-PNUD_Ocampo-final.pdf

OIT (2017). Panorama Laboral 2013 América Latina y el Caribe. Lima: Organización Internacional del Trabajo (OIT).

OIT (2013). Panorama Laboral 2013 América Latina y el Caribe. Lima: Organización Internacional del Trabajo.

Sátyro, Natália e Cunha, Pedro, (2015): "Why understanding social protection heterogeneity on the Brazilian municipalities matters? The coexistence of welfare regimes in a same country, a comparative analysis". Paper prepared to 2015 Annual ESPAnet Conference Denmark, 3-5 September 2015. 
Schumpeter, J., (1984); "Capitalismo, socialismo y democracia". Ed. Folio, Barcelona.

Traversa, Federico y Carneiro Fabricio 2017 "Presidencialismo, juicio político y deterioro del vínculo democrático en América Latina". Religación. Revista de Ciencias Sociales y Humanidades, Vol II • Num. 7, Quito, pp. 48-62

Valencia, E. (2012). "Segmentación y estratificación del sistema de salud en México: actores y raíces históricas". En (Des) Encuentros entre las reformas sociales, salud, pobreza y desigualdad en América Latina. Buenos Aires: Universidad de Quilmes, CLACSO.

Wood, Geof, (2013); "Situating informal welfare within imperfect well- being regimes Journal of International and Comparative Social Policy, 31:2, 132-150.

Wilensky, Harold L., (1975): The Welfare State and Equality: structural and ideological roots of public expenditures. California: University of California.

\section{Resumo}

No início do século XXI, a América Latina inaugurou um estágio de recuperação econômica acompanhado por uma importante mudança política, relacionada à qual as forças de esquerda assumiram os governos em um grupo de países. Nesse período, os países do Cone Sul (Brasil, Argentina, Chile e Uruguai) registraram melhorias significativas no bem-estar, explicadas não apenas pelo crescimento da época, mas também porque a luta distributiva foi processada nos sistemas democráticos. As explicações acadêmicas supunham que, na fase de desaceleração econômica regional, ajustes moderados seriam produzidos essencialmente pela própria dinâmica democrática. $O$ objetivo deste artigo é mostrar os avanços e inovações em proteção social no Cone Sul nos últimos quinze anos. Simultaneamente, como objetivo complementar, pretende-se testar explicações para um cenário conjuntural, sobre as reformulações que estão sendo processadas em termos de proteção, tendendo a limitar e cortar os benefícios públicos.

\section{Dados dos autores}

María del Carmen Midaglia

Doctor en Ciencia Política, Profesor titular del Departamento de Ciencia Política de la Facultad de Ciencias Social, Universidad de la República, Montevideo-Uruguay. Especialista en temas de bienestar social y reforma socioeconómica. Correo electrónico: midaglia@gmail.com

Marcelo Castillo

Lic. en Ciencia Polícia, docente e investigador del Departamento de Ciencia Política de la Facultad de Ciencias Sociales de la Universidad de la República, Montevideo - Uruguay. Correo electrónico: mcastillofernandez@gmail.com 